\title{
How Does Knowledge Diffusion Impact Maintenance Performance? Lessons from a Survey in a Brazilian Petrochemical Company
}

\author{
Renelson Ribeiro Sampaio ${ }^{1}$, Francisco Uchoa Passos ${ }^{1}$, José Ricardo Tavares de Lima ${ }^{2}$ \& \\ Alex Álisson Bandeira Santos ${ }^{1}$ \\ ${ }^{1}$ College Senai Cimatec, Salvador, Brazil \\ ${ }^{2}$ Oxiteno S/A, Brazil \\ Correspondence: Francisco Uchoa Passos, College Senai Cimatec, Salvador, Brazil. E-mail: \\ francisco.uchoa@fieb.org.br \\ Received: April 24, 2014 \\ Accepted: May 12, 2014 \\ Online Published: June 25, 2014 \\ doi:10.5539/ibr.v7n7p48 \\ URL: http://dx.doi.org/10.5539/ibr.v7n7p48
}

\begin{abstract}
Continuous process industries depend on complex systems that operate in uninterrupted cycles using diversified resources, such as dedicated equipment; process and auxiliary materials; production and maintenance personnel; as well as several types of services. Maintenance services are an important element of these resources, focusing on asset preservation and improvement. To perform satisfactory work, maintenance teams increasingly appear to depend on the streams of knowledge that flow through them. The main objective of this paper is to investigate the relationship between the diffusion of organisational knowledge through the social network of a maintenance team and the performance indicators of the team. We conducted a survey in a Brazilian petrochemical company by collecting data from four maintenance teams. To examine that relationship we used, respectively, two proxies: the Overall Performance Index (OPI) and the Knowledge Diffusion Index (KDI). A positive correlation between OPI and KDI was noted, indicating that diffusion of organisational knowledge should be, to a certain extent, stimulated as a way of contributing to the improvement of the maintenance performance of the team.
\end{abstract}

Keywords: maintenance management, performance measurement, organisational knowledge creation, knowledge diffusion, social network analysis

\section{Introduction}

Continuous process industries comprise complex systems that operate in uninterrupted cycles, applying resources such as heavy equipment, production and delivery personnel, maintenance employees, materials, and a number of specific services that follow programs and plans to produce goods to satisfy client requirements. Maintenance activities stand out among other services in continuous process industries as a method for preserving the integrity, safety and availability of processes, thereby contributing to the maximisation of output and minimising operational losses.

Maintenance techniques are guided by value-adding criteria normally defined by an adopted management model that generate plans and intervention programs, which determine the actions required to achieve the desired outcomes. As a rule, maintenance plans and programs are designed, applied and periodically reviewed as a result of critical analysis, and they are performed to maintain their alignment with the organisational strategy. From these analyses, several indicators arise to assess the performance of a maintenance team. The groups of indicators can be associated to form a structure for evaluating the performance of a maintenance team.

It is assumed that the performance of a maintenance team is influenced by the existent level of organisational knowledge accumulated as a consequence of the diffusion of useful information among the team members. Similar results were studied in other industries such as automotive and telecommunication (Sampaio, Moraes, \& Passos, 2013; Sampaio, Rosa, \& Pereira, 2012).

Within the process of performing maintenance actions, knowledge is dynamically created and transmitted. Some parts of such knowledge are relevant to further routine actions and other parts are relevant to decision making related to improvement of maintenance activity. It is expected that a management system that promotes better conditions for the diffusion of knowledge could benefit from significant improvement of maintenance performance. 
The main objective of this paper is to investigate the dynamic relationship between the diffusion of knowledge through the social networks of maintenance teams and the performance of those teams. To evaluate this relationship we have proposed to apply two specific indexes and investigate the correlation between them. The first one is a global performance index for maintenance teams, represented by the proxy OPI (Overall Performance Index). The second one is associated to the condition of knowledge diffusion in a social network and is represented by the proxy KDI (Knowledge Diffusion Index).

This paper continues with a short review of the measurement of maintenance performance, considering its most commonly adopted indicators and suggesting a general framework for choosing performance indicators (Section 2). Section 3 presents a review of social network analysis, focusing on information/knowledge centralisation and diffusion. Section 4 provides a multi-case study and analysis data from four maintenance teams, each one performing at a site of a Brazilian petrochemical company. The aim of the analysis is to find an association between the OPI and KDI. Section 5 presents the conclusion of this paper.

\section{Measurement of Maintenance Performance}

Parida and Kumar (2006) enumerate the reasons that led to the adoption of a system for measuring the maintenance performance of a team.

Principally, measurement of the value added by a maintenance team is the most important goal. It is necessary to know whether the maintenance team does what is needed for the process and whether its results contribute to the business. Such a contribution would justify the maintenance investments made by the organisation, demonstrating that it produces an adequate return on the applied resources. Health, safety and environmental aspects are also objectives to encourage measuring the performance of a maintenance team because its activities contribute to the elimination of diseases, accidents and environmental effects.

New strategies for operation and maintenance are continually applied in response to market demands. Metrics are needed to evaluate the efficiency and effectiveness of adaptation actions to these new strategies and practices. Additionally, organisational structure changes with time as follows: horizontal and compact structures, the virtualisation of work, and self-managed teams, among others, have effects on the performance of maintenance services. Measurement systems should be employed to evaluate the effects of these organisational innovations.

According to Pun and White (1996), continuous monitoring should be established to ensure the successful use of a performance measurement system as well as to control information and provide feedback to promote its own improvement. The efficient use of information, focused on improving the operation and based upon proper tools, is a relevant aspect of the success of these actions.

Tsang (1998) indicates that maintenance requires a significant investment in physical assets and plays a key role in the overall performance of the organisation. The participation of maintenance activities in the total cost of the organisation is generally significant, although the level of participation depends on the segment of business considered. In a continuous process industry, the contribution to total costs is particularly expressive.

According to Dwight (1999), a first approach to performance measurement of a maintenance team is to assess its value, based on the minimisation of expenses for the existing assets. The main objective should be to increase future income. The volatile nature of the future income concept in organisations, usually guided by the need for short-term survival, restricts maintenance funds, although it is presumed that the management is aware of the consequences of these decisions. Again, the focus is restricted to an analysis of financial performance. For example, the postponement of major maintenance of a machine potentially reduces its future capacity and reliability. Future possible losses should be considered in the face of the benefit of reducing the immediate expenses. The implementation of an analysis based on future earnings projections becomes generally impractical for routine use.

According to Parida and Chattopadhyay (2007), the implementation of an adequate performance measurement of a maintenance team is needed to measure the effectiveness of actions taken, which justifies the investments in this activity. It is recommended that such a measurement system encompass financial and nonfinancial aspects, adopting the identical criteria used for measuring general performance throughout the organisation. The criteria for evaluation can be quantitative and qualitative. Some examples of quantitative measures are related to quality such as production (lost or increased capacity), the amount of waste generated, productivity, number of accidents, number of short and long stops, customer's claims and costs. Qualitative measurements include worker satisfaction and environmental issues, among others. Without a formal system of performance measurement it is difficult to plan, execute, monitor and properly improve the maintenance process.

Another argument by Parida and Chattopadhyay (2007) is that maintenance performance indices could be used 
to monitor the team members' performance as it relates to customer satisfaction and broader aspects such as health and safety, environmental protection, financial results, and the overall efficiency of the facilities, among other applications. Some of these metrics are classified in the category of leading indicators whereas others are classified in the category of lagging indicators. Some examples of leading indicators are as follows: condition-monitoring metrics such as measurements of noise, vibration, thermography and lubrication oil analysis. By monitoring these metrics it is possible to understand the individual equipment conditions at a particular time, ensuring that it is possible to predict the individual equipment conditions in the future and to plan specific preventive actions case by case to avoid catastrophic failures. In the other category, overall maintenance costs and the mean time between failures (MTBF) are examples of lagging indicators. They are useful indices for understanding the overall past performance and tendencies of equipment and can be used to define the general preventive actions to be adopted.

The relevant data should be recorded and analysed at regular intervals to control maintenance and related activities, creating favourable conditions for decision-making and defining corrective and preventive actions. The indices of performance measurement can be based, for example, on goals associated with deadlines or on assessment of trends. If the index is positive and stable, indicating that everything is working fine, then the action can be to maintain the current status. If the index is negative or has exceeded the acceptable deviation from the target, then the decision will be to act immediately. Whenever the difference falls within acceptable limits, the decision will be to make a stricter observation of the process. Different types of charts and figures can be used to indicate the status of the index, using different category levels for performance results, such as "excellent", "satisfactory" or "unsatisfactory" or "requiring improvement", as suggested by Parida and Kumar (2006).

A system for measuring maintenance performance should consider all the requirements according to the views of different stakeholders. These criteria can be divided into integrated performance indices from the strategic level to the operational level. Figure 1 illustrates how these indices should be derived from the vision, objectives and strategy of an organisation, observing the requirements of the internal and external stakeholders.

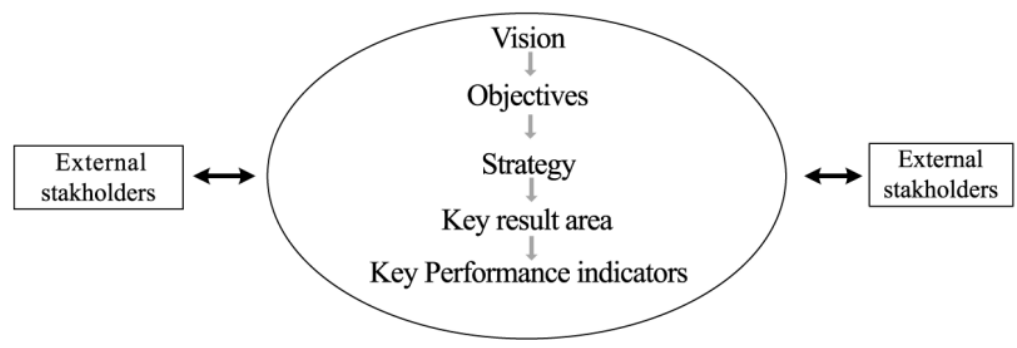

Figure 1. Developing and identifying performance indices from the vision, objectives, strategy and operation

Source: Parida and Chattopadhyay (2007).

Another way to view the system is to consider the basic levels of the organisational hierarchy, as represented in Figure 2. In general, organisations have three or more hierarchy levels in deployment. A system for measuring the maintenance performance should consider, at least, a corporative level (strategic), a tactical level (managerial) and a functional level (operational). The proper integration of informational exchanges among these levels is a challenge to be overcome. Involving all the employees in the process of defining and measuring the maintenance performance indices appears to be a very important decision to enact. It is known that the measured performance of a maintenance team depends on decisions previously taken for each one of these levels. For example, decisions about centralisation or decentralisation of maintenance and about whether these activities will be kept in-house or outsourced are made at the strategic level. Decisions related to the budget, skills, inventory, preventive maintenance, condition monitoring, intervals between operations, repairs, replacements and overhaul are examples of decisions that occurred at the tactical and operational levels. 


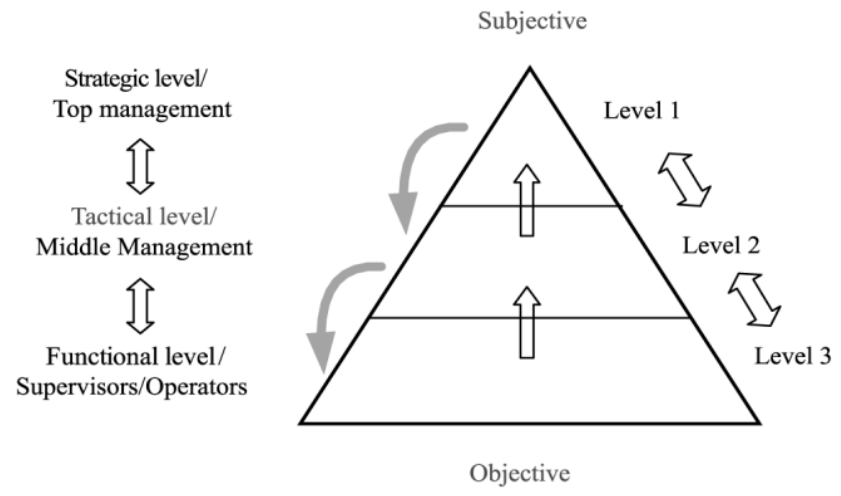

Figure 2. Developing and identifying performance indices from hierarchy levels

Source: Parida and Chattopadhyay (2007).

As Figure 2 shows, the strategic goals are transformed by managers into operational objectives that work as drivers for a desired performance. Reverse flow occurs during integration of the functional objectives from the operational level to achieve Key Performance Indices (KPI) (Parida and Chattopadhyay 2007) at the strategic level. These authors suggested a multi-criteria hierarchical structure for measuring the maintenance performance of a team (Figure 3). In accordance with their framework, there are seven categories (multi-criteria) of indicators of performance, which are deployed into three hierarchical levels. As seen in Figure 3, the categories are related as follows: equipment and production; cost and finance; maintenance activities; learning and growth; customer satisfaction; health, integrity, safety and environment; and employee satisfaction. The framework is intended to guide managers in choosing maintenance performance indicators. In the actual planning and development activities there are several possible alternatives to monitor maintenance performance, and the best option should be chosen for managing that function in a particular organisation. In accordance with the criteria of the hierarchical levels of management, the framework is based on consolidation logic, i.e., the level 1 metrics are the consolidation of the level 2 metrics, and the level 2 metrics are the consolidation of the level 3 metrics.

\begin{tabular}{|c|c|c|c|c|}
\hline \multirow{4}{*}{$\begin{array}{l}\text { Front-end process } \\
\text {-Timely delivery } \\
\text {-Quality } \\
\text {-HSE issues } \\
\text { External } \\
\text { Effectiveness } \\
\text {-Customers/ } \\
\text { stakeholders } \\
\text {-Compliance with } \\
\text { regulations }\end{array}$} & \multirow{2}{*}{$\begin{array}{l}\text { Hierarchica } \\
\text { criteria }\end{array}$} & Level 1 & Level 2 & Level 3 \\
\hline & & $\begin{array}{r}\text { Strategic/Top } \\
\text { management }\end{array}$ & $\begin{array}{c}\text { Tactical/Middle } \\
\text { management }\end{array}$ & $\begin{array}{l}\text { Functional/ } \\
\text { Operational }\end{array}$ \\
\hline & $\begin{array}{l}\text { Equipment/ } \\
\text { Process } \\
\text { related }\end{array}$ & - Capacity utilization & $\begin{array}{l}\text { - Availability } \\
\text { - OEE } \\
\text { - Production rate } \\
\text { - Quality } \\
\text { - Number of stops }\end{array}$ & $\begin{array}{l}\text { - Production rate } \\
\text { - Number of defects/rework } \\
\text { - Number of stops/downtime } \\
\text { - Vibration \& thermography }\end{array}$ \\
\hline & $\begin{array}{c}\text { Cost/finance } \\
\text { related }\end{array}$ & $\begin{array}{l}\text { - Maintenance budget } \\
\text { - ROMI }\end{array}$ & $\begin{array}{l}\text {-Mintenance production cost } \\
\text { per ton } \\
\text { - Maintenance/production cost }\end{array}$ & - Mintenance cost per ton \\
\hline regulations & $\begin{array}{c}\text { Maintenance } \\
\text { task related }\end{array}$ & - Cost of maintenance tasks & $\begin{array}{l}\text { - Quality of maintenance taska } \\
\text { - Change over time } \\
\text { - Planned maintenance task } \\
\text { - Unplanned maintenance task }\end{array}$ & $\begin{array}{l}\text { - Change over time } \\
\text { - Planned maintenance task } \\
\text { - Unplanned maintenance } \\
\text { task }\end{array}$ \\
\hline $\begin{array}{l}\text { Internal } \\
\text { Effectiveness }\end{array}$ & $\begin{array}{l}\text { Learning } \\
\text { growth \& } \\
\text { innovation }\end{array}$ & $\begin{array}{l}\text { - Generation of a } \\
\text { number of new ideas } \\
\text { - Skill improvment } \\
\text { training }\end{array}$ & $\begin{array}{l}\text { - Generation of number } \\
\text { of new ideas } \\
\text { - Skill improvement } \\
\text { training }\end{array}$ & $\begin{array}{l}\text { - Generation of number } \\
\text { of new ideas } \\
\text { - Skill improvement } \\
\text { training }\end{array}$ \\
\hline $\begin{array}{l}\text {-Productivity } \\
\text {-Efficiency } \\
\text {-Growth \& }\end{array}$ & $\begin{array}{l}\text { Customer } \\
\text { satisfaction } \\
\text { related }\end{array}$ & $\begin{array}{l}\text { - Quality complaint number } \\
\text { - Quality return } \\
\text { - Customer satisfaction } \\
\text { - Customer retaintion }\end{array}$ & $\begin{array}{l}\text { - Quality complaint numbers } \\
\text { - Quality return } \\
\text { - Customer satisfaction } \\
\text { - New customer addition }\end{array}$ & $\begin{array}{l}\text { - Quality complaint } \\
\text { numbers } \\
\text { - Quality return } \\
\text { - Customer satisfaction }\end{array}$ \\
\hline Back-end process & $\begin{array}{l}\text { Health, safety } \\
\text { \& Security, } \\
\text { environment }\end{array}$ & $\begin{array}{l}\text { - Number of accidents } \\
\text { - Number of legal cases } \\
\text { - HSSE losses } \\
\text { - HSSE complaints }\end{array}$ & $\begin{array}{l}\text { - Number of accidents/incidents } \\
\text { - Number of legal cases } \\
\text { - Compensation paid } \\
\text { - HSSE complaints }\end{array}$ & $\begin{array}{l}\text { - Number of accidents/ } \\
\text { incidents } \\
\text { - HSSE complaints }\end{array}$ \\
\hline $\begin{array}{l}\text {-Supply chain } \\
\text {-HSE }\end{array}$ & $\begin{array}{c}\text { Employee } \\
\text { satisfaction }\end{array}$ & $\begin{array}{l}\text { - Employee satisfaction } \\
\text { - Employee complaints }\end{array}$ & $\begin{array}{l}\text { - Employee turnover rate } \\
\text { - Employee complaints }\end{array}$ & $\begin{array}{l}\text { - Employee absentees } \\
\text { - Employee complaints }\end{array}$ \\
\hline
\end{tabular}

Figure 3. Multi-criteria hierarchical structure for maintenance performance measurement

Source: Parida and Chattopadhyay (2007). 
A systemic comprehension of the firm requires a view of its internal processes as well as its interface processes with the business environment in the front-end and the back- end operations (Figure 3). The front-end processes should be measured according to the needs of the stakeholders such as the customers, owners, lenders, and regulatory authorities. The front-end processes include requirements for the delivery time, the quality and the HSE issues (health, safety and security). The internal processes are measured in terms of capacity, capability, reliability, productivity, efficiency, growth and innovation, among others. Finally, the back-end processes have the following type of metrics: the stability of the deliveries from suppliers, the supply chain issues and the HSE issues.

\section{Social Network Analysis}

To evaluate the effects of knowledge diffusion on the maintenance performance, this work investigates the fluxes of information in the social networks of maintenance teams. A short review of the social network analysis follows.

Graph theory is used to represent social networks as a model system composed of sets of actors and links between them, called relations or ties. This model is a simplified representation of the network that follows some (but certainly not all) of the elements of reality represented. Based on graph theory, points (called nodes) are used to represent actors, and lines connecting the points are used to represent the links between the actors. The representation of a network in a graph form (also called a sociogram) ensures that it is easier to visualise and identify the patterns in the relationships studied. Another form used to represent and summarise the data of networks is a matrix, which contains the identical information as the graphs, but is more suited for computer analysis. In this particular work, we used only sociograms, considering the representation of directional relations, where the lines are routed from one node to another. The directed graphs, called digraphs can be used to represent the directional relationships where a link has necessarily an origin and a destination (Wasserman \& Faust, 2009).

In directed networks we can evaluate the number of arcs leaving a given node, as well as the number of arcs that reach this node. When two actors are linked to each other, reciprocity is established, and in networks in which there is a greater frequency of reciprocity, greater knowledge diffusion tends to occur.

The network related variables considered relevant to this survey are as follows: the averages of "nodal indegree" and "nodal outdegree"; the "information centrality"; and the "knowledge diffusion index" (KDI).

\subsection{Nodal Indegree and Nodal Outdegree}

Nodal indegree is the number of rows adjacent to a node, or equivalently, the number of arcs incident from a given network node. In a graphical representation, a node can be adjacent to a node or incident from another node, depending on the direction of the arc. It is necessary to consider the two cases separately. Nodal outdegree quantifies the tendency of actors to "make choices", whereas nodal indegree quantifies the tendency to be "chosen". Nodal indegree measures the responsiveness or the popularity of actors, whereas nodal outdegree measures the expansiveness of the identical node.

The average nodal indegree and nodal outdegree of all the actors in a social network can be measured using the mean values calculated with the formulas (1) presented below.

$$
\text { Indegree }=\bar{d}_{i}=\frac{\sum_{i-1}^{g} d_{i}\left(n_{i}\right)}{g} ; \quad \text { Out deg ree }=\bar{d}_{o}=\frac{\sum_{i-1}^{g} d_{o}\left(n_{i}\right)}{g} ; \quad \bar{d}_{i}=\bar{d}_{o}=\frac{L}{g}
$$

Nodal indegree and nodal outdegree calculation formulas

Source: Wasserman and Faust (2009).

The term ni represents each of the network nodes; di represents the number of nodes that are adjacent to a node, $\mathrm{ni}$; do represents the number of nodes that are adjacent to the node, ni; and $\mathrm{g}$ represents the total number of nodes. In a complete analysis of the networks, the average nodal indegree and nodal outdegree are equal and correspond to the ratio between the number of arcs (represented by L) and the number of actors (represented by $\mathrm{g}$ ).

\subsection{Information Centrality}

Many network centrality measures (such as degree, intermediation and proximity) are widely used, but, in general, only the geodesic paths (the shortest link between nodes) are considered in their calculation. Because information in a network can flow using any available path, Stephenson and Zelen (1989) proposed a new method to calculate centrality in a social network analysis, which was named information centrality. This 
concept is based on statistical theory and considers all existing links between actors, analysing the information contained in each path. This method does not consider who transmits the information to whom, but rather if there is any way in which the information can flow.

The information centrality calculation method is provided by this formula (2), in which Dij is a measure of the distance between actors, corresponding to the number of lines in each interconnecting path. Iij corresponds to the reciprocal of this distance measure, called the information measure of each path, and IC is a measure of the information centrality of a network with $\mathrm{n}$ actors.

$$
I C=\sum_{i=1}^{n} I_{i} \text { where } I_{i}=\frac{n}{\sum_{j=1}^{n} \frac{1}{I_{i j}}} \text { and } I_{i j}=\frac{1}{D_{i j}}
$$

Information centrality calculation formula

Source: Stephenson and Zelen (1989).

\subsection{Knowledge Diffusion Index (KDI)}

The knowledge diffusion index measures the knowledge socialisation level existing among the network members. KDI, as initially proposed by Rosa (2008), can be obtained by multiplying two factors, the average nodal indegree (or nodal outdegree) and information centrality.

Formula (3) shows the mathematical representation of the knowledge diffusion index (KDI).

$$
K D I=\left(\frac{L}{g}\right) \times I C
$$

Knowledge Diffusion Index calculation formula

Source: Rosa (2008).

\section{Maintenance Performance Face to Knowledge Diffusion-A Multi-Case Study}

The main objective of this study is to investigate the association between the performance of maintenance teams and their existing conditions for knowledge diffusion. To achieve this goal it was decided initially to investigate these aspects for six maintenance teams of a Brazilian petrochemical company operating in plants installed at sites throughout the country. The study addressed two sets of variables. The first set corresponds to the variables associated with performance measurement of a maintenance team as discussed in Section 2. The second set corresponds to the variables associated with favourable conditions for knowledge diffusion in a network as outlined in Section 3. A survey was given to the six teams to collect the two sets of variables. Subsequently, the manner in which each set related to the other was verified.

\subsection{Collecting the Indicators of Maintenance Performance-the Overall Performance Index (OPI)}

To propose an index for the overall maintenance performance of a team, the idea of a hierarchical multi-criteria structure was followed. To be representative of the entire company, a survey investigating the performance index was conducted in six important industrial plants of the company; three plants were located in Bahia state, one in Rio Grande do Sul state and two in São Paulo state. In this paper they are identified as sites A to F, respectively, to preserve information confidentiality.

An array of 29 maintenance performance indicators were selected from the multi-criteria framework suggested by Parida and Chattopadhyay (2007), and we asked the manager of each team to indicate which of these indicators are effectively adopted by his team to monitor its performance. Figure 4 shows a chart representing the frequency of adoption of the indicators by teams. These frequencies show how the use of each indicator is spread throughout the company. In general, 25 indicators are more frequently applied at the sites, and three or more sites apply these 25 indicators for their performance measurement. We used these indicators to construct the set of 25 performance variables. 


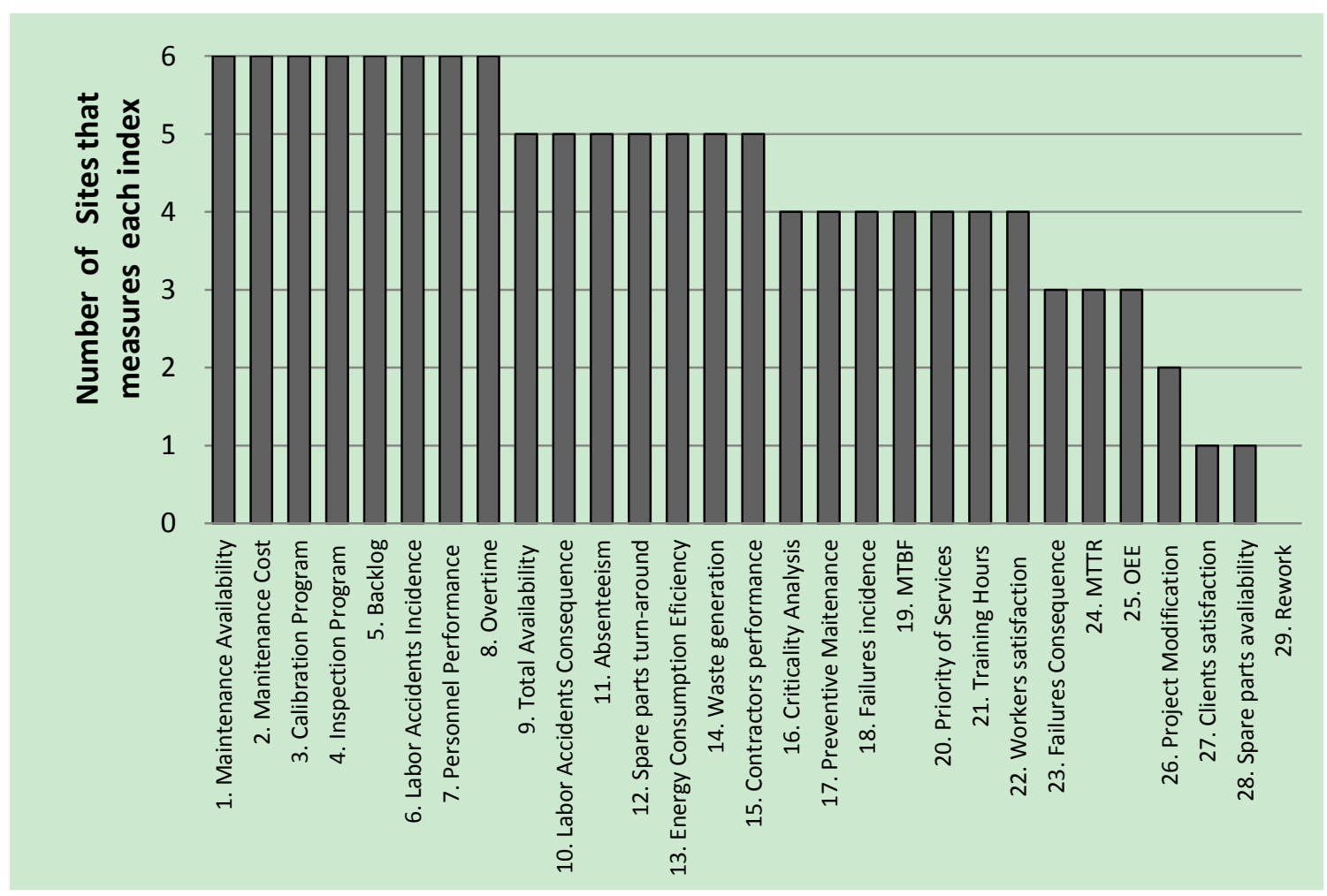

Figure 4. Maintenance performance indicators-frequency of adoption

Source: the authors.

The next step was to calculate an overall performance index (OPI) for each team, and to do that, we used the identical criteria employed in a survey developed by the Brazilian Maintenance Association (Abraman, 2009) to investigate the general condition of maintenance function in the country. A score and a weight for each of the 25 indicators of the set was shown. The score represents the degree of excellence of an indicator for a particular site. The weight represents the hierarchical importance of an indicator to the management.

The scores were valued on a scale from 0 to 10, as detailed in Appendix A. Score 10 was attributed to the best result found, and score 0 was attributed to sites that had no measurement of that specific indicator. Although this assumption can cause some distortion (because no measurement of a specific task does not necessarily represent poor task performance), it was considered that this possible distortion is not relevant for this case study because few measures with a score equal to zero were found.

A questionnaire was given to gather the scores of the set of performance indicators among 117 members of the six maintenance teams. A total of 81 useful responses provided a satisfactory evaluation of the excellence degrees for each of the 25 performance indicators reached in each site.

Two values were adopted for weight as follows:

Weight 6 was attributed to the strategic and tactical indicators with a significant effect on the performance of maintenance according to the multi-criteria hierarchical structure for maintenance performance measurement (see Figure 3). Examples of this type of indicator are those that are associated with the following factors: availability and maintenance downtime; maintenance costs and output quality; and the incidence and consequence of labour accidents. Strategic and tactical indicators are directly related to the expectations of the stakeholders.

Weight 3 was attributed to operational indicators, which have less effect than the strategic and tactical outcomes of maintenance. Examples of this type of indicator are those that are related to operational tasks including the following: monitoring of the mean time between failures; the lubrication, inspection and calibration schedule; the spare parts turn-around; internal training; waste control; the follow-up of contractor performance and monitoring of corrective actions, among others.

The values established for the weights ( 6 or 3 ) were based on the consensus of the maintenance managers of the 
surveyed sites.

From the data related to the scores and weights, it was possible to calculate the Overall Performance Index (OPI) of each team, applying formula (4), in which:

$i=1$ to 25 , being representative of the order of each of the 25 indicators of the set;

$\mathrm{S}(\mathrm{i})=$ score for the indicator " $\mathrm{i}$ " order;

$\mathrm{W}(\mathrm{i})=$ weight for the indicator "i" order.

$$
\mathrm{OPI}=\sum_{1}^{25} S(i) W(i)
$$

Overall Performance Index calculation formula

Source: the authors.

The OPI was calculated for each site investigated, as detailed in Appendix B, resulting in the final values as represented in Figure 5.

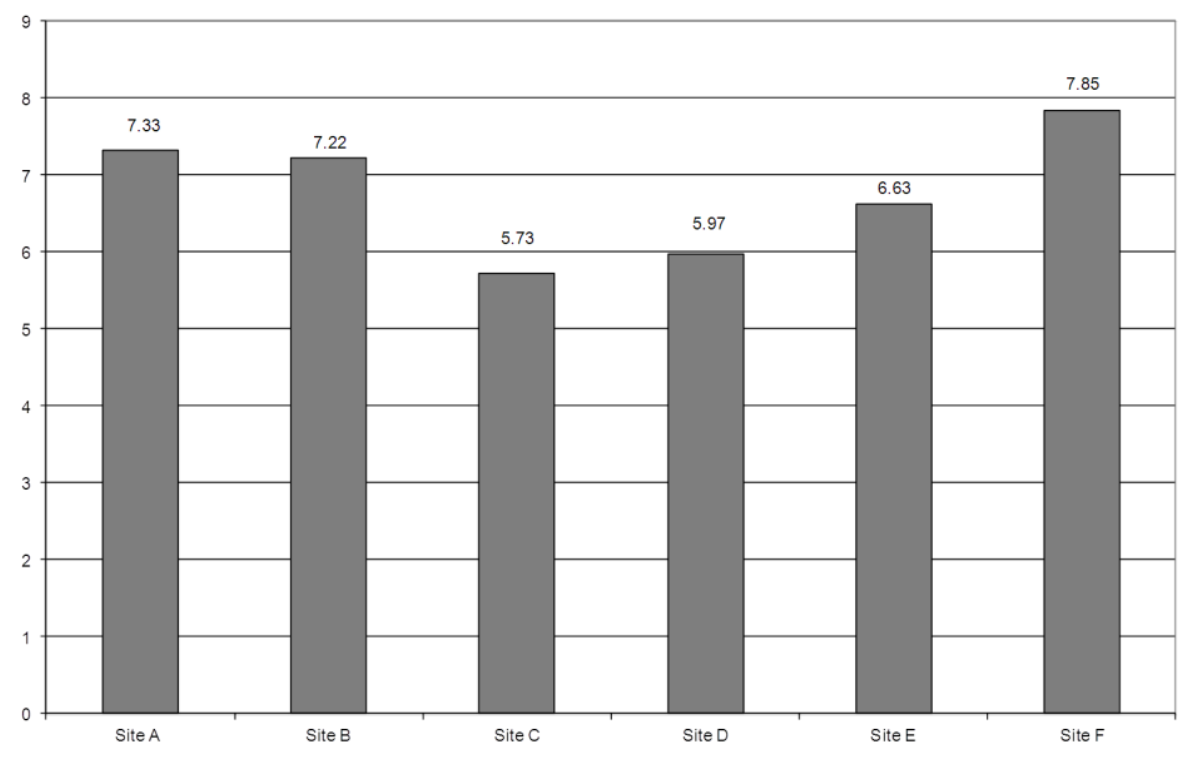

Figure 5. Overall Performance Index (OPI) per site

Source: the authors.

\subsection{Collecting the Indicators of Knowledge Diffusion-the Knowledge Diffusion Index (KDI)}

To map the network of knowledge diffusion for each site, a questionnaire was designed primarily to collect information about the relationships among the team members for the implementation of their tasks. This questionnaire was applied to the identical 117 members of the six maintenance teams as the questionnaire calculating the overall performance index in sub-section 4.1. From their responses, it was possible to identify the existing relationships within each team, particularly the information sources and destinations, to calculate the most important network parameters such as the nodal indegree/outdegree, the information centrality and the knowledge diffusion index (KDI).

To assess the relationship in a team as realistically as possible, we used only survey data from teams with participation of over $80 \%$ of its total workforce. The responses from sites $\mathrm{D}$ and $\mathrm{E}$ were discarded, and the knowledge diffusion data were restricted to sites A, B, C and F, which were the only sites to reach the percentage of responses considered satisfactory for adequate representation. We considered the particularities of sites $\mathrm{A}$ and $\mathrm{B}$ because the maintenance team members from sites A and B work together in the same facilities and are supervised by the same manager. In this condition, the analysis of their networks was conducted as one single team (represented by "site A/B team") composed of 47 members identified from A-01 to A-47 in Figure 6. Sites $\mathrm{C}$ and $\mathrm{F}$ were composed of 10 and 5 members, respectively, with members identified as C-01 to C-10 and F-01 to F-05 in Figures 7 and 8. 
The described data gathered during the research fieldwork allowed us to formulate an analysis of three existing social networks identified as A/B, C and F, as shown in Figures 6, 7 and 8.

Each link between two actors (the maintenance team members) was defined according to their responses to the questionnaire and represents the existence of one or more reciprocal communication relationships established to seek information during maintenance activities. Overall, these links provide a clear picture of each network at a given period of time and graphically represent the existing recorded interactions. They indicate the complexity and density of the interactions between the actors in the network.

These processes of information exchange carried out by team members are primarily based on their tacit knowledge of the routine work, and they are particularly to clarify specific issues related to problem solving activities and improvement suggestions. Eventually, the technical solution achieved will be transformed into explicit knowledge as a formal procedure to be adopted and registered in the best practices blueprint of the company.

This type of relationship, which is actually a process of 'learning by doing', is repeated throughout the maintenance team network, fostering continuous improvement of the overall performance of the team. Each of the 25 maintenance performance indicators selected to construct the Overall Performance Index (OPI) reflects a particular feature of this rich and complex learning process.

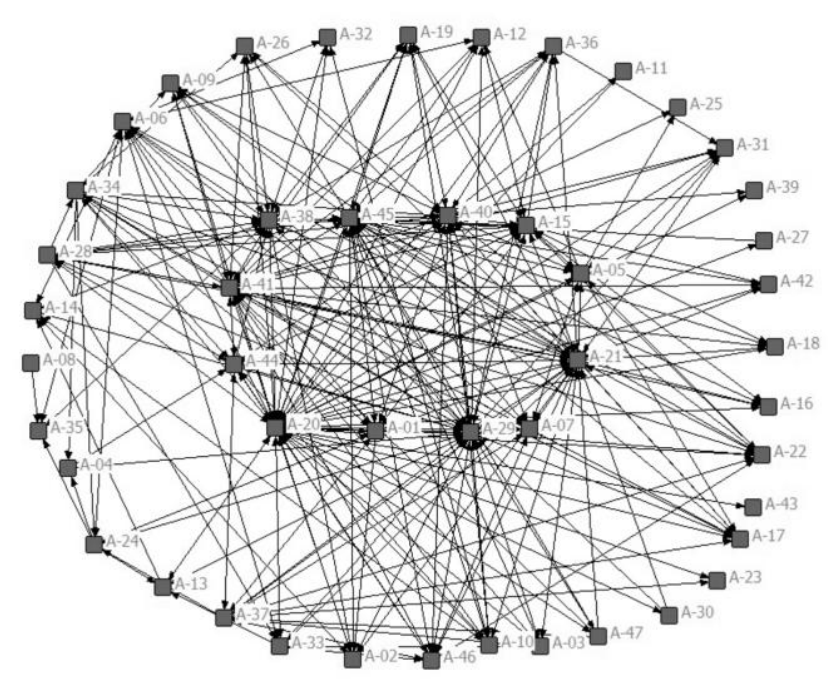

Figure 6. maintenance team network of the Units A and B

Source: the authors by using Netdraw Software.

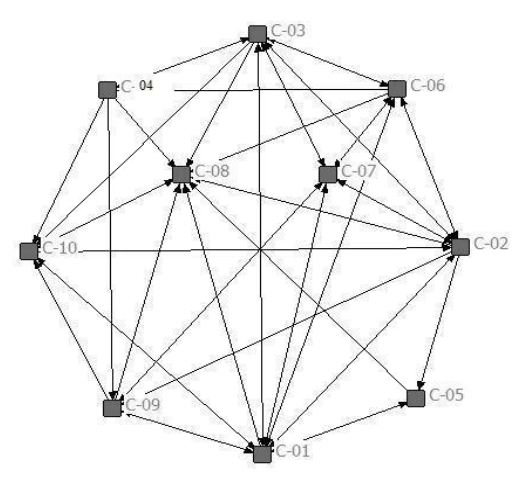

Figure 7. Maintenance team network of the Unit C

Source: the authors using Netdraw Software. 


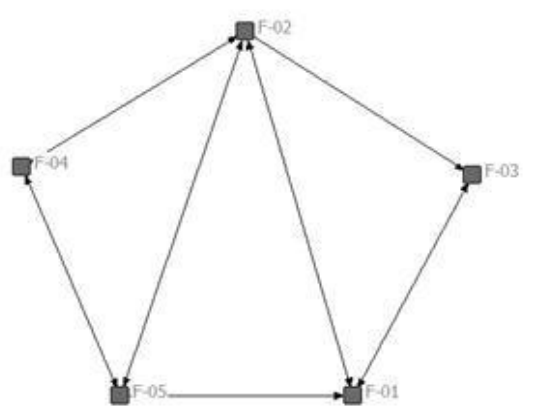

Figure 8. Maintenance team network of the Unit F

Source: the authors using Netdraw Software.

A matrix for each of the three networks was assembled using Ucinet software, which shows the relationship between the actors. The crossings of the rows and columns represent actor involvement, and the corresponding cells show the amount of socialised information. It was assumed that this amount of information indicates the degree of importance of the link between the actors within the social network.

For each matrix, the average nodal indegree and outdegree were initially calculated using the Ucinet software, adopting the non-symmetric mode, to consider the inclusion of the values of the diagonals. The option of including the values of the diagonals is because some survey respondents made a self-reference to the production or use of the knowledge generated that was considered an actual fact, and these references should be included in the analysis. Subsequently, the information centralities were calculated including the values of the diagonals for the same reason as for the calculation of nodal indegree and outdegree. From the average nodal indegrees/outdegrees and information centralities, the KDI values were calculated in accordance with formula (3) (see section 3). Table 1 shows the figures for sites A, B, C and F, where the last column exhibits the values for the corresponding OPIs. The figures related to the networks (the nodal indegree/outdegree, centrality and KDI) for sites A and B are identical because they constitute one network.

Table 1. Knowledge Diffusion Index (KDI) per site

\begin{tabular}{ccccc}
\hline & Nodal Indegree / Outdegree & Information Centrality & KDI & OPI \\
\hline Site A & 37.19 & 9.85 & 3.66 & 7.33 \\
Site B & 37.19 & 9.85 & 3.66 & 7.22 \\
Site C & 20.3 & 9.71 & 1.97 & 5.73 \\
Site F & 38.4 & 15.17 & 5.82 & 7.85 \\
\hline
\end{tabular}

Source: the authors using Ucinet software.

\subsection{Relationship between OPI and KDI}

The figures presented in Table1 show that better maintenance performance, as measured by the overall performance index (OPI), was obtained at the sites with a correspondingly higher knowledge diffusion index (KPI). These results suggest that there is a correlation between the performance of a maintenance team and favourable conditions for knowledge diffusion in its social network. We could conclude that a team with favourable conditions for knowledge diffusion (represented by a social network with higher than average rates of nodal indegree/outdegree and information centrality) enables information to "travel" by its network with higher "speed" and lower "noise" levels, explaining their best performance. Figure 9 shows graphically a correlation between the OPI and KDI, based on the data obtained in this survey for sites A, B, C and F. 


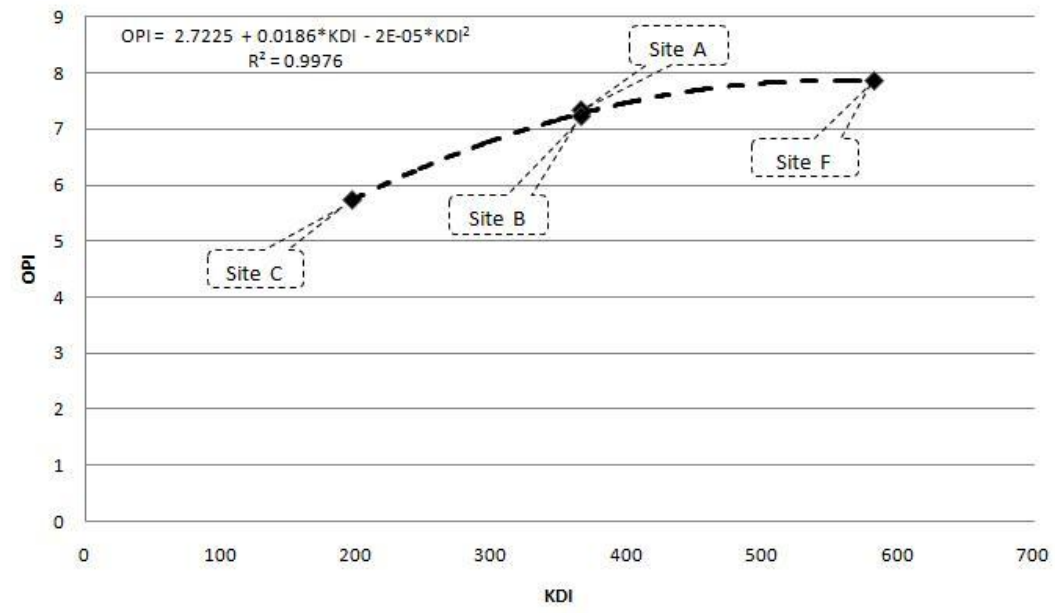

Figure 9. Correlation between OPI and KDI

Source: the authors.

An increase in the knowledge diffusion index (KDI) corresponds to an increase in the overall performance index (OPI). It appears that a method of obtaining better maintenance performance would be to improve the team capacity for knowledge diffusion. This conclusion is in accordance with common sense that it is possible to obtain incremental improvement in organisational performance by increasing the efforts directed at socialisation of the knowledge applied to produce the desired results. Figure 9 represents this relationship in the form of a trend line, for which the polynomial equation was calculated in formula [5] that fits the set of points with a correlation coefficient $\mathrm{R} 2=0.9976$.

$$
O P I=2.7225+0.0186 \times(K D I)-2 \times 10^{-5} \times(K D I)^{2}
$$

Correlation between the OPI and KDI

Source: the authors.

The proposed correlation model allows us additionally to conclude the following in the case of the investigated sites:

a) The OPI has a value approximately equal to 2.7 , for a KDI value equal to zero. The KDI value of zero could result from an average nodal indegree/outdegree equal to zero and/or from an information centrality equal to zero. We understand that the maintenance teams with a minimum level of knowledge diffusion can produce some results, although this level will most likely be considered lower than expected by the organisation.

b) Organisational maturity improvement normally requires a greater effort to produce performance increases beyond those already obtained. The proposed model shows that a reduction of favourable conditions for knowledge diffusion results in an increasing loss of performance.

c) The OPI has a maximum value of approximately 8 points on a scale from 0 to 10 , corresponding to a KDI equivalent of approximately 6.5 points. Apparently, the efforts to increase the knowledge diffusion beyond this point would not result in improvement in performance because the curve shows decreasing marginal increments of the OPI. This finding could be explained by considering that very high knowledge diffusion intensity causes information overload, reflecting in decreasing performance results.

\section{Final Remarks}

This work determined that a significant part of the knowledge that a team member applies is composed of captured information from other members with whom he/she has a relationship during the performance of his/her tasks within the team. The survey respondents indicated that to solve problems they obtain information by consulting other members of their social network inside the team in addition to following formal procedures and documents.

In continuous processing industries, it is generally accepted that documents and formal procedures are the most important source of information because of the high risk involved in their operation and integrity. The study shows that constructing knowledge networks and exploiting their interactions among team members could be a 
very important way to achieve a higher level of work performance.

This paper reveals that team performance appears to be influenced by favourable conditions for knowledge diffusion among team members. The knowledge diffusion index (KDI) could be used as a metric of these conditions. The results presented in this paper indicate that managers should consider the benefits of improving the knowledge diffusion conditions within their teams for improving performance.

It is important to note that the proposed correlation between the OPI and the KDI is based on an exploratory study performed with a small number of maintenance teams. The correlation that was determined, as well as the associated conclusions, must be considered representative within the limits of the survey. Future research extending the approach in this work to the study of social networks in other types of activities is suggested to validate the hypothesis that the relationship between overall performance and knowledge diffusion is independent of the type of organisation and network.

\section{Acknowledgments}

We express our gratitude to Flávio Cavalcanti and many others at Oxiteno, the Brazilian petrochemical company where we performed this survey. We also express our special thanks to Chaeyoon Lim and Trevor Young-Hyman for their comments and helpful remarks. All the errors are our own.

\section{References}

Abraman. (2009). A situação da manutenção no Brasil - Documento Nacional. 24o. Congresso Brasileiro de Manutenção.

Borgatti, S. P. (2002). NetDraw: Graph Visualization Software. Harvard: Analytic Technologies.

Borgatti, S. P., Everett, M. G., \& Freeman, L. C. (2002). Ucinet for Windows: Software for Social Network Analysis. Harvard, MA: Analytic Technologies.

Cross, R., Borgatti, P. S., \& Parker, A. (2002). Making Invisible Work Visible- Using Social Network Analysis to Support Strategic Collaboration. California Management Review, 44, 23. http://dx.doi.org/10.2307/41166121

Cross, R., Nohria, N., \& Parker, A. (2002). Six Myths About Informal Networks - and How To Overcome Them. MIT Sloan Management Review, 43, 11.

Cross, R., Parker, A., Prusak, L., \& Borgatti, S. P. (2001). Knowing what we know: Supporting knowledge creation and sharing in social networks. Organizational Dynamics, 30, 100-120. http://dx.doi.org/10.1016/S0090-2616(01)00046-8

Dwight, R. (1999). Searching for real maintenance performance measures. Journal of Quality in Maintenance Engineering, 5(3), 258-275. http://dx.doi.org/10.1108/13552519910282728

Janhonen, M., \& Johanson, J. E. (2010). Role of knowledge conversion and social networks in team performance. International Journal of Information Management, In Press, Corrected Proof.

Kratzer, J., Leenders, R. T. A. J., \& Van Engelen, J. M. L. (2009). A social network perspective on the management of product development programs. The Journal of High Technology Management Research, 20, 169-181. http://dx.doi.org/10.1016/j.hitech.2009.09.005

Kratzer, J., Leenders, R. T. A. J., \& Van Engelen, J. M. L. (2010). The social network among engineering design teams and their creativity: A case study among teams in two product development programs. International Journal of Project Management, 28, 428-436. http://dx.doi.org/10.1016/j.jproman.2009.09.007

Nonaka I., \& Takeuchi, H. (1997). Criação de conhecimento na empresa: como as empresas japonesas geram a dinâmica da inovação. Campus.

Parida, A., \& Chattopadhyay, G. (2007). Development of a multi-criteria hierarchical framework for maintenance performance measurement. Journal of Quality in Maintenance Engineering, 13(3), 241-258. http://dx.doi.org/10.1108/13552510710780276

Parida, A., \& Kumar, U. (2006). Maintenance Performance Measurement (MPM): issues and challenges. Journal of Quality in Maintenance Engineering, 12(3), 239-251. http://dx.doi.org/10.1108/13552510610685084

Pun, K., \& White, A. (1996). A performance measurement paradigm for integrating strategy formulation: a review of systems and frameworks. International Journal of Management Reviews, 7(1), 49-71. http://dx.doi.org/10.1111/j.1468-2370.2005.00106.x

Rosa, C. (2008). Aplicação da Análise de Rede Social no Processo de Difusão do Conhecimento de Tecnologia 
de Informação na Organização. Dissertação (Mestrado Interdisciplinar em Modelagem Computacional) Faculdade Visconde de Cairu, Salvador.

Sampaio, R. R., Moraes, M., \& Passos, F. U. (2013). Fluxos de informação e conhecimento no desenvolvimento de produto na indústria automotiva - uma comparação entre as redes formal e informal. Produção Online, 13(1), 208-232. http://dx.doi.org/10.14488/1676-1901.v13i1.1112

Sampaio, R. R., Rosa, C. P., \& Pereira, H. B. d. B. (2012). Mapeamento dos fluxos de informação e conhecimento: a governança de TI sob a ótica das redes sociais. Gestão \& Produção, 19, $377-387$. http://dx.doi.org/10.1590/S0104-530X2012000200011

Stephenson, K., \& Zelen, M. D. (1989). Rethinking centrality: methods and examples. Social Networks, 11(1), 1-37. http://dx.doi.org/10.1016/0378-8733(89)90016-6

Tsang, A. (1998). A strategic approach to managing maintenance performance. Journal of Quality in Maintenance Engineering, 4(2), 87-94. http://dx.doi.org/10.1108/13552519810213581

Wasserman, S., \& Faust, K. (2009). Social Network Analysis. Cambridge: Cambridge University Press.

\section{Appendix}

Appendix A. Scores and weights for maintenance performance indicators

\begin{tabular}{|c|c|c|c|c|c|c|c|c|}
\hline Indicator & $\begin{array}{c}\text { REFERENCE } \\
\text { (ABRAMAN) }\end{array}$ & Weight & Site A & Site B & $\begin{array}{l}\text { Results } \\
\text { Site C }\end{array}$ & Site D & Site E & Site F \\
\hline Global Availability & $96,50 \%$ & $6 \%$ & 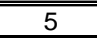 & 2 & 9 & 9 & 9 & 9 \\
\hline Maintenance Unavailability & $2,50 \%$ & $6 \%$ & 10 & 10 & 10 & 10 & 4 & 10 \\
\hline Maintenance Cost / Investment & $2,60 \%$ & $6 \%$ & 6 & 8 & 0 & 6 & 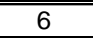 & 9 \\
\hline Maintenance Cost / Billing & $3,17 \%$ & $6 \%$ & 9 & 6 & 0 & 7 & 7 & 7 \\
\hline Training Hours & $3,10 \%$ & $3 \%$ & 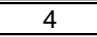 & 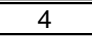 & 0 & 6 & 0 & 8 \\
\hline Absenteeism & Not available & $3 \%$ & 8 & 8 & 0 & 9 & 10 & 0 \\
\hline Turn-over & $2,00 \%$ & $3 \%$ & 4 & 10 & 10 & 2 & 10 & 10 \\
\hline Electrical Motors MTBF & Not available & $3 \%$ & 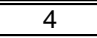 & 3 & 0 & 3 & 0 & 10 \\
\hline Mechanical Seals MTBF & Not available & $4 \%$ & 10 & 5 & 0 & 3 & 0 & 5 \\
\hline Calibration Program & Not available & $3 \%$ & 10 & 10 & 10 & 10 & 10 & 10 \\
\hline Non Conformities & Not available & $6 \%$ & 4 & 4 & 0 & 0 & 0 & 6 \\
\hline Inspection Program & Not available & $3 \%$ & 10 & 10 & 10 & 8 & 0 & 10 \\
\hline Process Accidents & Not available & $6 \%$ & 7 & 7 & 10 & 5 & 10 & 4 \\
\hline Labor Accidents Incidence & 0,95 & $6 \%$ & 10 & 10 & 10 & 2 & 10 & 10 \\
\hline Labor Accidents Consequence & 48,25 & $6 \%$ & 10 & 10 & 10 & 5 & 10 & 10 \\
\hline Waste generation & Not available & $3 \%$ & 2 & 6 & 0 & 10 & 0 & 4 \\
\hline Backlog & Not available & $3 \%$ & 10 & 10 & 10 & 10 & 10 & 10 \\
\hline Contractors Performance & Not available & $3 \%$ & 10 & 10 & 10 & 10 & 10 & 10 \\
\hline Corretive Maintenance & $29,85 \%$ & $3 \%$ & 3 & 3 & 3 & 3 & 9 & 5 \\
\hline Lubrication Program & Not available & $3 \%$ & 10 & 10 & 10 & 9 & 10 & 10 \\
\hline Mechanical Preventive Maintenance & Not available & $3 \%$ & 10 & 10 & 10 & 3 & 10 & 10 \\
\hline Electrical Preventive Maintenance & Not available & $3 \%$ & 10 & 10 & 10 & 6 & 10 & 10 \\
\hline Safety Valves Preventive Maintenance & Not available & $3 \%$ & 8 & 10 & 10 & 10 & 10 & 10 \\
\hline Spare Parts cost / maintenance cost & $13,1 \%$ & $3 \%$ & 4 & 4 & 0 & 2 & 1 & 2 \\
\hline Spare parts turn-around & 5 months & $3 \%$ & 2 & 2 & 0 & 6 & 9 & 6 \\
\hline
\end{tabular}


Appendix B. Overall performance index calculation per site

\begin{tabular}{lcccccc}
\hline \multicolumn{1}{c}{ Indicator } & \multicolumn{7}{c}{ Results per Site } & \\
\cline { 2 - 7 } & Site A & Site B & Site C & Site D & Site E & Site F \\
\hline \hline Global Availability & 0,40 & 0,16 & 0,72 & 0,72 & 0,72 & 0,72 \\
\hline Maintenance Unavailability & 0,80 & 0,80 & 0,80 & 0,80 & 0,32 & 0,80 \\
\hline \hline Maintenance Cost / Investment & 0,48 & 0,64 & 0,00 & 0,48 & 0,48 & 0,72 \\
\hline Maintenance Cost / Billing & 0,72 & 0,48 & 0,00 & 0,56 & 0,56 & 0,56 \\
\hline \hline Training Hours & 0,08 & 0,08 & 0,00 & 0,12 & 0,00 & 0,16 \\
\hline Absenteeism & 0,16 & 0,16 & 0,00 & 0,18 & 0,20 & 0,00 \\
\hline Turn-over & 0,08 & 0,20 & 0,20 & 0,04 & 0,20 & 0,20 \\
\hline \hline Electrical Motors MTBF & 0,16 & 0,12 & 0,00 & 0,12 & 0,00 & 0,40 \\
\hline Mechanical Seals MTBF & 0,40 & 0,20 & 0,00 & 0,12 & 0,00 & 0,20 \\
\hline \hline Calibration Program & 0,20 & 0,20 & 0,20 & 0,20 & 0,20 & 0,20 \\
\hline Non Conformities & 0,32 & 0,32 & 0,00 & 0,00 & 0,00 & 0,48 \\
\hline \hline Inspection Program & 0,20 & 0,20 & 0,20 & 0,16 & 0,00 & 0,20 \\
\hline Process Accidents & 0,28 & 0,28 & 0,40 & 0,20 & 0,40 & 0,16 \\
\hline Labor Accidents Incidence & 0,80 & 0,80 & 0,80 & 0,16 & 0,80 & 0,80 \\
\hline Labor Accidents Consequence & 0,80 & 0,80 & 0,80 & 0,40 & 0,80 & 0,80 \\
\hline Waste generation & 0,04 & 0,12 & 0,00 & 0,20 & 0,00 & 0,08 \\
\hline \hline Backlog & 0,30 & 0,30 & 0,30 & 0,30 & 0,30 & 0,30 \\
\hline Contractors Performance & 0,20 & 0,20 & 0,20 & 0,20 & 0,20 & 0,20 \\
\hline Corretive Maintenance & 0,09 & 0,09 & 0,09 & 0,09 & 0,27 & 0,15 \\
\hline \hline Lubrication Program & 0,20 & 0,20 & 0,20 & 0,18 & 0,20 & 0,20 \\
\hline Mechanical Preventive Maintenance & 0,20 & 0,20 & 0,20 & 0,06 & 0,20 & 0,20 \\
\hline Electrical Preventive Maintenance & 0,20 & 0,20 & 0,20 & 0,12 & 0,20 & 0,20 \\
\hline Safety Valves Preventive Maintenance & 0,16 & 0,20 & 0,20 & 0,20 & 0,20 & 0,20 \\
\hline \hline Spare Parts cost / maintenance cost & 0,08 & 0,08 & 0,00 & 0,04 & 0,02 & 0,04 \\
\hline Spare parts turn-around & 0,04 & 0,04 & 0,00 & 0,12 & 0,18 & 0,12 \\
\hline Global Performance Indicator (GPI) & 7,33 & 7,22 & 5,73 & 5,97 & 6,63 & 7,85 \\
\hline
\end{tabular}

\section{Copyrights}

Copyright for this article is retained by the author(s), with first publication rights granted to the journal.

This is an open-access article distributed under the terms and conditions of the Creative Commons Attribution license (http://creativecommons.org/licenses/by/3.0/). 